\title{
Validity of self reported occupational exposures to hand transmitted and whole body vibration
}

\author{
Keith T Palmer, Barbara Haward, Michael J Griffin, Holly Bendall, David Coggon
}

\begin{abstract}
Objectives-To assess the accuracy with which workers report their exposure to occupational sources of hand transmitted (HTV) and whole body vibration (WBV). Methods-179 Workers from various jobs involving exposure to HTV or WBV completed a self administered questionnaire about sources of occupational exposure to vibration in the past week. They were then observed at work over 1 hour, after which they completed a second questionnaire concerning their exposures during this observation period. The feasibility of reported sources of exposure during the past week was examined by questioning managers and by inspection of tools and machines in the workplace. The accuracy of reported sources and durations of exposure in the 1 hour period were assessed relative to what had been ob-
\end{abstract} served.

Results-The feasibility of exposure in the previous week was confirmed for $97 \%$ of subjects who reported exposure to HTV, and for $93 \%$ of subjects who reported exposure to WBV. The individual sources of exposure reported were generally plausible, but occupational use of cars was substantially overreported, possibly because of confusion with their use in travel to and from work. The accuracy of exposures reported during the observation period was generally high, but some sources of HTV were confused-for example, nailing and stapling guns reported as riveting hammers, and hammer drills not distinguished from other sorts of drill. Workers overestimated their duration of exposure to HTV by a median factor of 2.5 (interquartile range (IQR) 1.6-5.9), but estimated durations of exposure were more accurate when the exposure was relatively continuous rather than for intermittent short periods. Reported durations of exposure to WBV were generally accurate (median ratio of reported to observed time 1.1, IQR 1.0-1.2).

Conclusions-Sources of recent occupational exposure to vibration seem to be reported with reasonable accuracy, but durations of exposure to HTV are systematically overestimated, particularly when the exposure is intermittent and for short periods. This raises the possibility that dose-response relations may have been biased in some of the studies on which exposure standards might be based, and that the levels in currently proposed standards may be too high. Future studies should pay attention to this source of error during data collection.

(Occup Environ Med 2000;57:237-241)

Keywords: vibration; exposure; assessment; validity

Traditionally, in epidemiological surveys of hand transmitted vibration (HTV) and whole body vibration (WBV), occupational exposures have been assessed from self reported histories of exposure. Sometimes these have been supplemented by measurement of contemporary exposures, ${ }^{1-5}$ and by historical records of the vibratory characteristics of tools used in earlier periods. ${ }^{6}$ Information on the number of years exposed workers have been employed in relevant jobs has been combined with their recalled daily patterns of exposure to estimate their cumulative exposure in terms of a total operating time (lifetime-hours) ${ }^{4-11}$ or vibration dose. $^{2-51213}$ Other techniques, including interviews with line managers and data on productivity, may also have been applied to refine dose estimates, although this is seldom reported explicitly. Only rarely has there been accurate independent documentary evidence of the true duration of exposures. ${ }^{14}$

The accuracy of estimated exposures has seldom been questioned, although anecdotal experience suggests that people exposed to HTV often confuse hand-tool contact time with the total time taken to complete tasks, and similar biases may exist in the reporting of exposure to WBV. In one survey, 343 Swedish subjects from 30 occupations who completed a questionnaire about physical workload on two occasions were found to report their durations of exposure to sources of HTV and WBV in a fairly repeatable manner, ${ }^{15}$ but this assessment was based on a semiquantitative scale; it did not encompass a comparison with direct observations; and no attempt was made to test the accuracy of recall so far as this related to specific sources of exposure. A few commentators have observed a disparity between workers' histories and their direct observations of daily durations of exposure, ${ }^{9}{ }^{16}$ but no reports have described the magnitude and direction of these differences, or the variables that influence them. It might be expected that those with only a few sources of exposure and those exposed in a fairly continuous fashion would provide more dependable accounts, but there is no published information on this.

We have therefore carried out a study to assess the validity of self reported exposure to occupational sources of vibration in comparison with direct observations and information 
supplied by employers. The work was undertaken primarily to determine the limitations of information that was being collected in a national postal survey described elsewhere, ${ }^{17} 18$ but the findings are of wider relevance to the problems of exposure assessment.

\section{Method}

The study was carried out at 19 fixed site workplaces, and on 65 vehicles selected to ensure representation of sources of exposure to vibration that are common in the national population. The workplaces comprised a plant where motor vehicles were manufactured; another where mattresses were assembled; a metalworking shop in a shipbuilder's yard; three farming and horticultural estates; an electrical utility; two retail warehouses; a haulage depot; a joinery; the works and gardens departments of a local authority and a university; and depots involved in the maintenance of aircraft, buses, police vehicles, and fire engines. The vehicles comprised a selection of vans, lorries, forklift trucks, buses, and tractors, driven by postal, road transport, warehouse, and agricultural workers employed by seven different employers.

Exposed workers in each workplace were selected for study on the basis of availability (range 1-22 workers). Each worker was asked to complete a questionnaire (identical to the exposure section of the postal questionnaire used in the national survey ${ }^{19}$ ), providing details of his or her occupational exposure to vibration in the previous week. The questionnaire asked about use of 64 named tools, machines, and vehicles. Also, there was an opportunity to report other sources of vibration in response to two open questions, the answers to which were reviewed and classified by an occupational physician (KTP) and a specialist in vibration research (MJG), blind to any other information about the subjects' exposures.

Subsequently, we interviewed line managers and inspected tool and vehicle inventories, depots, and store cupboards, to establish whether the reported sources of exposure were feasible, and to identify any that clearly had been incorrectly described.

After completion of the questionnaire, the workers were observed (by $\mathrm{BH}$ ) over a 1 hour period during representative activities that involved exposure to HTV, WBV, or both. A record was made of the sources of exposure, and for each source, the period during which vibration entered the body was measured with a stopwatch.

After this period of observation, the worker was asked to complete a second questionnaire, similar to the first but describing the exposures that had occurred during the time that he or she had been observed. These questionnaires were completed immediately after the observation period, or at the earliest available work break. (The sequence of events was such that the observer's records were completed without knowledge of the workers' reports.) A record was made of when the questionnaires were completed and whether or not the worker regarded the observation period as typical of
Table 1 Feasibility of reported occupational exposure to sources of vibration in the past week

\begin{tabular}{lcc}
\hline & $\begin{array}{l}\text { Workers } \\
\text { reporting } \\
\text { exposure } \\
(n)\end{array}$ & $\begin{array}{l}\text { Reports feasible } \\
(\%)\end{array}$ \\
Source of exposure & 14 & 86 \\
\hline Floor polisher & 21 & 86 \\
Nut runner & 21 & 62 \\
Impact wrench & 14 & 93 \\
Impact screwdriver & 37 & 84 \\
Jig saw & 20 & 80 \\
Circular saw & 13 & 100 \\
Hand guided mower & 22 & 86 \\
Hammer drill & 16 & 19 \\
Riveting hammer or dolly & 16 & 81 \\
Nailing or stapling gun & 22 & 77 \\
Pedestal grinder & 35 & 74 \\
Hand held portable grinder & 30 & 87 \\
Hand held sander & & \\
Any source of hand & 125 & 97 \\
$\quad$ transmitted vibration & 14 & 36 \\
Car & 32 & 81 \\
Van & 16 & 94 \\
Bus or coach & 13 & 85 \\
Tractor & 27 & 93 \\
Fork lift truck & 16 & 100 \\
Lorry & & \\
Any source of whole body & 95 & 93 \\
$\quad$ vibration & & \\
\hline
\end{tabular}

the job. The sources and durations of exposure reported in answer to the second questionnaire were compared with those found.

\section{Results}

A total of 166 male and 13 female workers were invited to take part in the study and all agreed. Their ages ranged from 16 to 63 years with a median of 40 years. The most common occupations in the sample were: drivers of forklift trucks (25), motor assembly workers (17), cleaners (13), metal plate workers, and shipwrights (12), gardeners and groundsmen (11), drivers of goods vehicles (10), bus drivers (9), motor mechanics (9), mattress makers (8), carpenters and joiners (7), van drivers (7), woodworking machinists (5), and metal working and maintenance fitters (5).

\section{EXPOSURES IN THE PAST WEEK}

One hundred and twenty five subjects reported exposure to HTV in the past week, and 95 reported exposure to WBV. These accounts were confirmed as feasible in $97 \%$ of the HTV group and $93 \%$ of the WBV group (table 1). However, when specific sources of exposure were considered, there was less accuracy. Altogether, 393 sources of exposure to HTV and 140 sources of exposure to WBV were reported. Of the HTV reports, 260 (66\%) were confirmed as plausible on independent inquiry, as were $106(76 \%)$ of the WBV reports. The proportion of reported exposures that were considered plausible varied according to the alleged source of vibration. For HTV it ranged from $19 \%$ for riveting hammers to $100 \%$ for hand guided mowers. For WBV the proportion was generally high, but it was only $36 \%$ for reported occupational use of cars.

\section{SOURCES OF EXPOSURE IN THE OBSERVATION} PERIOD

After the 1 hour period of observation in the workplace, 166 subjects (93\%) completed the second questionnaire within an hour, and eight 
Table 2 Agreement between reported and observed sources of exposure to vibration over a 1 hour period

\begin{tabular}{|c|c|c|c|c|}
\hline Source of exposure & $\begin{array}{l}\text { Workers } \\
\text { reporting } \\
\text { exposures } \\
\text { (n) }\end{array}$ & $\begin{array}{l}\text { Workers } \\
\text { observed to be } \\
\text { exposed } \\
\text { (n) }\end{array}$ & $\begin{array}{l}\text { Sensitivity } \\
(\%)\end{array}$ & $\begin{array}{l}\text { Specificity } \\
(\%)\end{array}$ \\
\hline Floor polisher & 13 & 13 & 100 & 100 \\
\hline Nut runner & 15 & 15 & 66 & 97 \\
\hline Impact wrench & 13 & 7 & 71 & 95 \\
\hline Impact screwdriver & 12 & 18 & 39 & 97 \\
\hline Jig saw & 12 & 13 & 69 & 98 \\
\hline Circular saw & 9 & 6 & 100 & 98 \\
\hline Hand guided mower & 10 & 10 & 100 & 100 \\
\hline Hammer drill & 16 & 30 & 53 & 100 \\
\hline Riveting hammer or dolly & 13 & 1 & 100 & 93 \\
\hline Nailing or stapling gun & 17 & 24 & 58 & 98 \\
\hline Hand held portable grinder & 12 & 14 & 86 & 100 \\
\hline Hand held sander & 13 & 10 & 90 & 98 \\
\hline $\begin{array}{l}\text { Any source of hand transmitted } \\
\text { vibration }\end{array}$ & 110 & 113 & 96 & 98 \\
\hline Van & 12 & 7 & 100 & 97 \\
\hline Bus or coach & 13 & 12 & 100 & 97 \\
\hline Tractor & 9 & 9 & 89 & 99 \\
\hline Fork lift truck & 24 & 25 & 96 & 100 \\
\hline Lorry & 10 & 7 & 100 & 98 \\
\hline $\begin{array}{l}\text { Any source of whole body } \\
\text { vibration }{ }^{\star}\end{array}$ & 73 & 65 & 97 & 91 \\
\hline
\end{tabular}

${ }^{\star}$ From the sources listed in the questionnaire.

others within 3 hours. For five others the time of completion was not recorded. Only one indicated that the observation period had not been typical of his job.

One hundred and thirteen subjects were seen to use hand held powered tools during the observation period, among whom 69 people used a single tool, 31 used two tools, eight used three, and five used five. This compared with 110 people who reported exposure during the period of observation (table 2). In this context the sensitivity of the questionnaire to detect exposure to HTV was $96 \%$, and its specificity was $98 \%$.

When individual sources of HTV were considered, 180 were recorded during the observation period compared with 179 reported. The sensitivity of reports varied by source from $39 \%$ for impact screwdrivers to $100 \%$ for circular saws, floor polishers, and hand guided mowers, whereas their specificity ranged from $93 \%$ to $100 \%$. In some cases, misclassification occurred between particular pairs of tools: eight of 10 subjects who reported exclusive exposure to a riveting hammer were actually using nailing and stapling guns; in three instances where hand held sanders were reported as used, only portable grinders had been seen; and eight of 29 subjects who only used a hammer drill reported using a riveting hammer. Another source of error lay in the inadequate description of some tools by subjects: in five subjects who were seen using a hammer drill, their various accounts of using a drill, an air drill, a portable drill, and a hand held drilling machine did not lead to them being classified as reported users of this tool.

Exposure to WBV was seen in 65 subjects, but only two of these had more than one source of exposure over the period of observation. Seventy three people reported having incurred exposure (table 2), so that the overall sensitivity of the questionnaire to detect exposure to WBV was $97 \%$ and its specificity was $91 \%$. The sensitivity of reported exposure to WBV varied by source, from $89 \%$ for tractors to $100 \%$ for vans, buses, and lorries. The specificity of reports by source was high $(97 \%-$ $100 \%)$.

So far as HTV was concerned, 131 subjects $(73 \%)$ provided an entirely accurate list of their sources of exposure over the observation period (table 3$)$. In a further 13 subjects $(7 \%)$, an exposure was reported that was not seen; in 14 subjects $(8 \%)$ an exposure was seen that was not reported; and in 21 others (12\%) there were elements of both overreporting and underreporting. For sources of exposure to WBV, the accounts of 165 people (92\%) were confirmed in all particulars by direct observation. In a further 10 subjects $(6 \%)$ an exposure was reported that was not seen; whereas three subjects failed to report an exposure that was seen $(2 \%)$, and one person both omitted to report a source of exposure and falsely reported another one.

REPORTED AND OBSERVED EXPOSURE DURATIONS Figures 1 and 2 compare the reported and observed durations of exposure to HTV and WBV. For HTV there was a marked tendency to overreport durations of exposure, a wide scatter of reported times for similar periods of true exposure, and a tendency to round estimates up or down to the nearest whole multiple of 5 or 10 minutes (digit preference). A few subjects reported exposure durations that were longer than the period of observation, illustrating the difficulties they had in understanding instructions. With WBV exposure, there was much less tendency to overreport exposure durations and less scatter, but similar evidence of digit preference.

The relation between reported and observed durations of exposure (median and interquartile range (IQR) of the ratios of reported to observed durations) was examined for different sources of exposure. In subjects exposed to HTV, the extent of overreporting ranged from

Table 3 Patterns of error and omission in reporting exposure to sources of vibration during a 1 hour period of observation

\begin{tabular}{|c|c|c|c|c|c|c|c|c|c|}
\hline \multirow[b]{2}{*}{ Observed exposure } & \multirow{2}{*}{$\begin{array}{l}\text { Subjects } \\
(n)\end{array}$} & \multicolumn{2}{|c|}{$\begin{array}{l}\text { Complete } \\
\text { agreement with } \\
\text { observation }\end{array}$} & \multicolumn{2}{|c|}{$\begin{array}{l}\text { Sources } \\
\text { reported but } \\
\text { not observed }\end{array}$} & \multicolumn{2}{|c|}{$\begin{array}{l}\text { Sources } \\
\text { observed but } \\
\text { not reported }\end{array}$} & \multicolumn{2}{|c|}{$\begin{array}{l}\text { Sources reported but not } \\
\text { observed and not all } \\
\text { observed sources reported }\end{array}$} \\
\hline & & $n$ & $\%$ & $n$ & $\%$ & $n$ & $\%$ & $n$ & $\%$ \\
\hline \multicolumn{10}{|c|}{ Hand transmitted vibration: } \\
\hline Exposed & 113 & 66 & 58 & 12 & 11 & 14 & 12 & 21 & 19 \\
\hline Not exposed & 66 & 65 & 98 & 1 & 2 & 0 & 0 & 0 & 0 \\
\hline Overall & 179 & 131 & 73 & 13 & 7 & 14 & 8 & 21 & 12 \\
\hline \multicolumn{10}{|c|}{ Whole body vibration: } \\
\hline Exposed & 65 & 61 & 94 & 0 & 0 & 3 & 5 & 1 & 2 \\
\hline Not exposed & 114 & 104 & 91 & 10 & 9 & 0 & 0 & 0 & 0 \\
\hline Overall & 179 & 165 & 92 & 10 & 6 & 3 & 2 & 1 & 1 \\
\hline
\end{tabular}




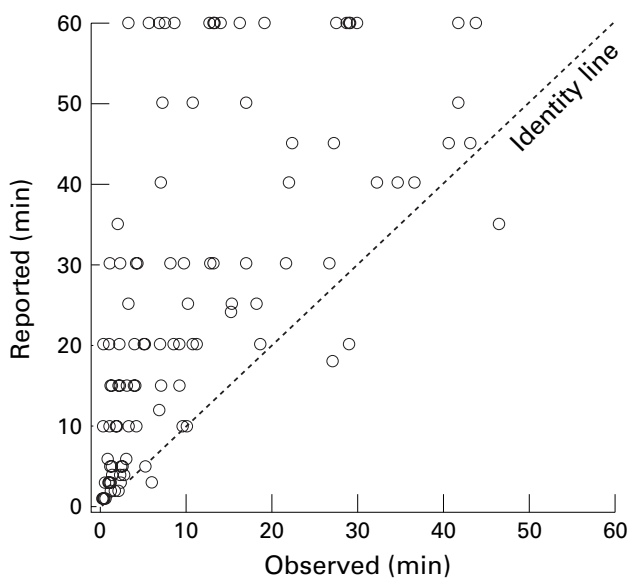

Figure 1 Reported and observed exposure times for sources of $H T V$.

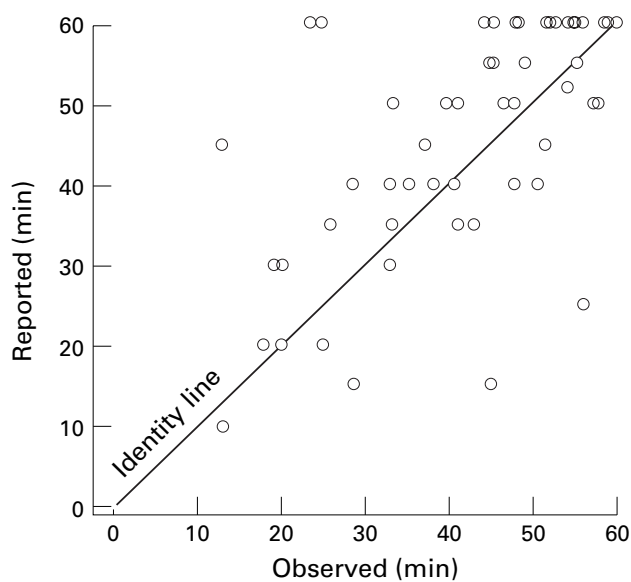

Figure 2 Reported and observed exposure times for sources of $W B V$.

a median of 1.2-fold (IQR 0.8-2.0) for hand guided mowers to 6.3-fold (IQR 3.4-7.6) for hand held sanders (table 4). Ratios were lowest for the three most continuous sources of exposure (those with the smallest median number of interruptions to exposure during the observation period).

Errors in reported durations of exposure to WBV were smaller than for HTV (table 4), and

Table 4 Ratio of reported to observed durations of exposure to sources of vibration

\begin{tabular}{|c|c|c|c|}
\hline \multirow[b]{2}{*}{ Source of exposure } & \multirow[b]{2}{*}{$\begin{array}{l}\text { Subjects* } \\
\text { (n) }\end{array}$} & \multicolumn{2}{|c|}{$\begin{array}{l}\text { Ratio of reported to observed } \\
\text { duration of exposure }\end{array}$} \\
\hline & & Median & $\begin{array}{l}\text { (Interquartile } \\
\text { range) }\end{array}$ \\
\hline Impact screwdriver & 7 & 4.0 & $(3.7-17.5)$ \\
\hline Nut runner & 8 & 3.0 & $(1.7-8.6)$ \\
\hline Nailing or stapling gun & 11 & 4.6 & $(2.3-6.9)$ \\
\hline Hammer drill & 6 & 2.7 & $(2.0-9.7)$ \\
\hline Hand held sander & 8 & 6.3 & $(3.4-7.6)$ \\
\hline Impact wrench & 5 & 5.6 & $(3.0-10.0)$ \\
\hline Jig saw & 8 & 3.5 & $(1.8-8.2)$ \\
\hline Hand held portable grinder & 11 & 2.1 & $(1.2-6.3)$ \\
\hline Hand guided mower & 10 & 1.2 & $(0.8-2.0)$ \\
\hline Floor polisher & 13 & 1.6 & $(1.4-1.9)$ \\
\hline Any source of hand transmitted vibration & 104 & 2.5 & $(1.6-5.9)$ \\
\hline Van & 6 & 1.2 & $(1.1-1.2)$ \\
\hline Bus or coach & 12 & 1.1 & $(1.0-1.2)$ \\
\hline Tractor & 8 & 1.1 & $(1.0-1.1)$ \\
\hline Fork lift truck & 24 & 1.0 & $(0.9-1.2)$ \\
\hline Lorry & 7 & 1.2 & $(1.0-1.5)$ \\
\hline Any source of whole body vibration & 62 & 1.1 & $(1.0-1.2)$ \\
\hline
\end{tabular}

^Analysis was restricted to subjects whose report of exposure was confirmed by observation. the overall ratio of reported to observed exposure durations was close to unity (median 1.1, IQR 1.0-1.2).

\section{Discussion}

Little attempt has been made previously to assess the accuracy of workers' accounts of their exposure to vibration. This is surprising given the evident difficulties in quantitative estimation, which include the need to differentiate between duration of exposure and the overall time taken to complete the task in which the exposure occurs, and the need to recall exposures that may be intermittent and irregularly spaced in time. These challenges seem particularly formidable in users of hand held vibratory tools, as they will often need to remember and identify several different sources of exposure used for comparatively short periods and for specific operations.

The main obstacle to validation of self reported histories of exposure is the difficulty in establishing a reliable standard against which to assess their accuracy without at the same time modifying subjects' recall. Accurate information on durations of exposure of individual workers to specific tools is not normally available retrospectively, and any attempt to record such information prospectively is likely to be noticed by the worker, and could therefore alter his awareness and later reporting of exposures. In the absence of an ideal study design, we considered the problem in three ways.

Firstly, we examined the feasibility of exposures that subjects reported in the past week. Our standard for this was information obtained from employers and from inspection of tools and machines used in the workplace. The fact that a reported exposure was by these criteria plausible does not necessarily imply that it was accurate. However, we were able to identify reports that were clearly inaccurate, and thus establish a minimum rate of error. In general such errors were rare, but problems did occur with some sources of HTV such as riveting hammers (only 19\% of reports confirmed as feasible), possibly because subjects confused them with other tools. Also, only $36 \%$ of the reported uses of cars in work were classified as plausible. The questionnaire distinguished between occupational and non-occupational use of private and public transport, and indicated that travel to and from work should be counted as non-occupational. However, this may not have been fully appreciated by those answering it.

A second component of the analysis compared reported exposures during a 1 hour period with those directly observed during this time. In this case a more reliable standard was available, but the test of reporting was less stringent insofar as subjects only had to recall exposures in the past few hours and during a time when they had known they were under observation. Nevertheless, the findings provide further reassurance that workers were in general able to name sources of exposure accurately. Exceptions to this were hammer drills, which were not always described with sufficient 
specificity, nailing and stapling guns which were sometimes reported incorrectly as riveting hammers, and portable grinders which in three cases were reported as hand held sanders.

The third part of the analysis focused on the time for which subjects were exposed to different sources of vibration during the 1 hour observation period. Again, the test of reporting was less demanding than if subjects had been questioned about exposures over a longer period and without any previous questioning or observation. Despite this, however, we found substantial overreporting of exposure times for intermittent sources. These were principally to HTV (exposure to WBV tended to be much more continuous), and in some cases the overreporting was by a factor of five or higher. Also, there was marked variation between people in the reliability with which exposure times were estimated. The commonly used index of vibration dose $(\mathrm{A}(8))$ is proportional to the square root of daily exposure time, ${ }^{2021}$ so that the median 2.5-fold overreporting of duration of exposure to HTV would lead to a $60 \%$ overestimate of dose.

Such a degree of overreporting may not arise in studies where sufficient care has been taken to verify workers' impressions of exposure times. Nevertheless, our data raise the possibility that currently proposed exposure standards may be too high. Many of the data underlying these standards come from research in the forestry industry where studies have focused on the chain saw, a tool that is used fairly continuously. ${ }^{22-27}$ However, findings on other tools, such as pedestal grinders, hand held grinders, rock drills, chipping hammers, and caulking guns ${ }^{12227-30}$ have also been taken into account, and in some investigations overestimation of exposure times may have biased dose-response relations.

The subjects included in our study came from a wide range of occupations with varied exposures to HTV and WBV. They were selected on the basis of their availability on the day that their workplace was visited, and all who were approached agreed to participate. It follows that the findings are likely to be fairly representative of industry more generally. They suggest that workers report sources of occupational exposure to vibration with reasonable accuracy, but tend systematically to overestimate the duration of their exposures, particularly where these are intermittent. This source of error must be taken into account along with others-for example, the vibration characteristics of individual tools and machines-when evaluating dose-response relations.

This work was supported by a grant from the Health and Safety Executive. We are grateful to the employers and employees who helped in assessment of the questionnaire, and to Vanessa Cox for her assistance in data handling. Denise Gould prepared this manuscript.

1 Taylor W, Pelmear PL, Pearson JCG. Vibration-induced white finger epidemiology. In: Taylor W, Pelmear PL, ed Vibration white finger in industry. London: Academic Press, 1975:1-13.

2 Bovenzi M, Cerri S, Merseburger A, et al. Hand-arm vibration syndrome and dose-response relation for vibration- induced white finger among quarry drillers and stonecarvers. Occup Environ Med 1994;51:603-11.

3 Bovenzi M, Franzinelli R, Mancini R, et al. Dose-response relation for vascular disorders induced by vibration in the fingers of forestry workers. Occup Environ Med 1995;52: 722-30.

4 Boshuizen HC, Bongers PM, Hulshof CTJ. Self-reported back pain in tractor drivers exposed to whole-body vibration. Int Arch Occup Environ Health 1990;62:109-15.

5 Boshuizen HC, Bongers PM, Hulshof CTJ. Self-reported back pain in fork-lift truck and freight-container tractor drivers exposed to whole-body vibration. Spine 1992;17: 59-65.

6 Palmer K, Crane G, Inskip H. Symptoms of hand-arm vibration syndrome in gas distribution operatives. Occup Environ Med 1998;55:716-21.

7 Matsumoto K, Itoh N, Kasamatsu T, et al. A study on subective symptoms based on total operating time of chain saw. Fapanese Fournal of Industrial Health 1977;19:22-8.

8 Miyashita K, Shiomi S, Itch N, et al. Epidemiological study of vibration syndrome in response to total hand-tool operating time. Br f Ind Med 1983;40:92-8.

9 Tominaga Y. Dose-response relation for the vibration syndrome. In: Brammer AJ, Taylor W, eds. Vibration effects on the hand and arm in industry. New York: Wiley, 1982.

10 Bovenzi M. Vibration white finger among stonedrillers/ cutters in the travertine industry. In: Proceedings of foint French-British meeting. Groupe Francais des Etudes des Effets des Vibrations sur l'Homme and U.K. Informal Group on Human Response to Vibration. Vandoeuvre, France, INRS: 26-28 September 1988.

11 Letz R, Cherniack MG, Gerr F, et al. A cross sectional epidemiological survey of shipyard workers exposed to handarm vibration. Br f Ind Med 1992;49:53-62.

12 Bovenzi M, Zadini A. Self-reported low back symptoms in urban bus drivers exposed to whole-body vibration. Spine 1992;17:1048-59.

13 Bovenzi M, Betta A. Low-back disorders in agricultural tractor drivers exposed to whole-body vibration and postural stress. Appl Ergon 1994;25:231-41.

14 Bongers PM, Hulshof CTJ, Dijkstra L, et al. Back pain and exposure to whole body vibration in helicopter pilots. Ergonomics 1990;33:1007-26.

15 Witkorin C, Hjelm EW, Winkel J, et al, the Stockholm MUSIC I Study Group. Reproducibility of a questionnaire for assessment of physical load during work and leisure time. F Occup Environ Med 1996;38:190-7.

16 Fright E. A task analysis of operations involving the use of selected hand tools associated with vibration-induced white finger [MSc thesis]. Loughborough, UK: Loughborough Uniger [MSc thesis]. Loughboro

17 Palmer KT, Griffin MJ, Bendall H, et al. Prevalence and pattern of occupational exposure to hand transmitted vibration in Great Britain: findings from a national survey. Occup Environ Med 2000;57:218-28.

18 Palmer KT, Griffin MJ, Bendall H, et al. Prevalence and pattern of occupational exposure to whole body vibration in Great Britain: findings from a national survey. Occup Environ Med 2000;57:229-36.

19 Palmer K, Coggon D, Pannett B, et al. The development of a self-administered questionnaire to assess exposures to hand-transmitted and whole-body vibration and their health effects. Fournal of Sound and Vibration 1998;215: 653-86.

20 International Organisation for Standardisation. Mechanical vibration: guidelines for the measurement and the assessment of human exposure to hand-transmitted vibration. Geneva: ISO, 1986. (ISO 5349.)

21 British Standards Institution. Measurement and evaluation of human exposure to vibration transmitted to the hand. London: BSI, 1987. (BS1 6842.)

22 Takagi S. Raynaud's phenomenon due to chain saw and chipping machine. Fpn Circ F 1968;32:99-110.

23 Futatsuka M. Studies on vibration hazards due to chain saw. Kumamota Medical fournal 1969;43:467-524.

24 Brammer AJ, Olson N, Piercy JE, et al. Noise and vibration of chain saws. 7 Acoust Soc Am 1972;51:142.

25 Taylor W, Pelmear PL, Pearson J. Raynaud's phenomenon in forestry chain saw operators. In: Taylor W, ed. The vibration syndrome. London: Academic Press, 1974:121-39.

26 Wakisaka I, Nakano A, Ando M. Raynaud's phenomenon in chain saw operators. Acta Med Kagoshima 1975;17:1-6.

27 Taylor W, Pearson JCG, Keighley GD. A longitudinal study of Raynaud's phenomenon in chain saw operators. In: Proceedings of the International Occupational Hand-arm Vibration Conference. Cincinnati, $\mathrm{OH}$ : Department of Health and Human Services, 1977:74. (NIOSH Publ No 77-170.)

28 Williams N, Riegert AL. Raynaud's phenomenon of occupational origin in uranium miners. Occup Health Rev 1961;13:3-8.

29 Lidström I-M. Vibration injury in rock driller, chisellers and grinders. In: Wasserman DE, Taylor W, Curry MG, eds. Proceedings of the International Occupational Hand-arm Vibration Conference. Cincinnati, OH: Department of Health and Human Services, 1977:77-83. (NIOSH Publ No 77-170.)

30 Chatteriee DS, Petrie A, Taylor W. Prevalence of vibrationinduced white finger in fluorspar mines in Weardale. $\mathrm{Br} F$ Ind Med 1978;35:208-18. 